\title{
Prosthetic heart valve thrombosis
}

\section{BBehija Hukeljić Berberović1*, -Nermir Granov², ZZina Lazović ${ }^{2}$, -Lejla Divovićc Domer Perva ${ }^{2}$}

'University Clinical Center Sarajevo, Sarajevo School of Science of Technology, Sarajevo, Bosnia and Herzegovina

${ }^{2}$ University Clinical Center Sarajevo, Sarajevo, Bosnia and Herzegovina
KEYWORDS: prosthetic valve thrombosis, thrombolytic drug.
CITATION: Cardiol Croat. 2019;14(3-4):47. | https://doi.org/10.15836/ccar2019.47

*ADDRESS FOR CORRESPONDENCE: Behija Hukeljić Berberović, Klinički centar Univerziteta u Sarajevu, Bolnička 25, 71000 Sarajevo, Bosnia and Herzegovina. / Phone: +387-33-297941. Fax: +387-33-298-522 / E-mail: behijaberberovic@yahoo.com ORCID: Behija Hukeljić Berberović, https://orcid.org/0000-0001-9583-4523 • Nermir Granov, https://orcid.org/0000-0002-6228-6230 Zina Lazović, https://orcid.org/0000-0002-0285-9631 • Lejla Divović, https://orcid.org/0000-0002-7953-9601 Omer Perva, https://orcid.org/0000-0003-2645-1558

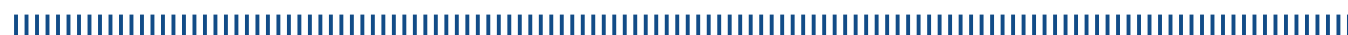

Prosthetic heart valve thrombosis is one of the most dreaded complications of mechanical heart valves. Suboptimal anticoagulation is the major risk for developing prosthetic heart valve thrombosis. Prosthetic heart valve thrombosis usually presents with dyspnea or embolic events ${ }^{1}$.

We present patient with prosthetic heart valve thrombosis without any symptoms, diagnosed via transthoracic echocardiography twenty days after mitral valve replacement during regular echocardiograph follow-up. In the medical history we obtained the information that the patient didn't take anticoagulation drugs for five days after hospital discharge. Transthoracic echocardiography control revealed reduced leaflet mobility and high transvalvular gradients: MV maxPG 22mmHg, MV meanPG 12mmHg (Figure 1). Transesophageal echocardiography showed the presence of thrombus on prosthetic valve measuring $11 \times 7 \mathrm{~mm}$. Patient was readmitted to the hospital and treated with thrombolytic drug alteplase. According to the American College of Cardiology/American Heart Association Guidelines fibrinolysis can be considered in a thrombosed left-sided prosthetic heart valve, which is of recent onset ( $<14$ days) with class I-II symptoms and a small thrombus on transesophageal echocardiography. Control echocardiography after treatment (Figure 2) showed MV meanPG $3.9 \mathrm{mmHg}$ and normal mobility of mitral valve. Successful thrombolytic therapy was followed by warfarin and intravenous unfractionated heparin until the INR is 3-4

Current American College of Cardiology/American Heart Association Guidelines assign Class I recommendation to transthoracic echocardiography or transesophageal echocardiography imaging in patient with prosthetic valve only in the presence of clinical symptoms or sings of valve dysfunction. Pathological studies and observational registries indicate that the risk of valve thrombosis highest in the first 3 month after surgical implantation of prosthetic valve, suggesting that anticoagulant thromboprophylaxis in this time frame may be beneficial. ${ }^{2}$ Early follow up after surgical implantation is important because early detection and treatment of thrombus formation may lead to shortterm reduction in the risk of TE events and long-term prevention of prosthetic valve degeneration

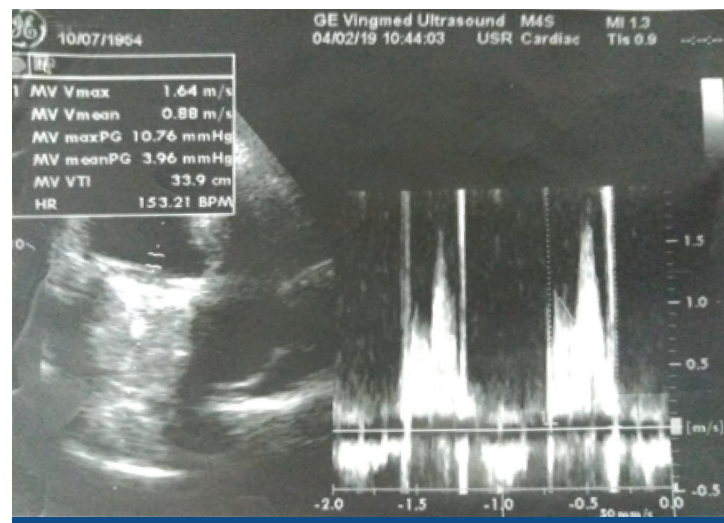

FIGURE 2. Control echocardiography after treatment showed: MV maxPG $10 \mathrm{mmHg}$, MV mean PG $3.9 \mathrm{mmHg}$
February 28, 2019

ACCEPTED:

March 24, 2019

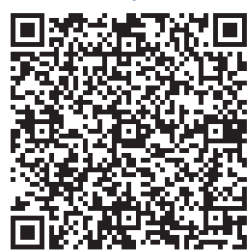

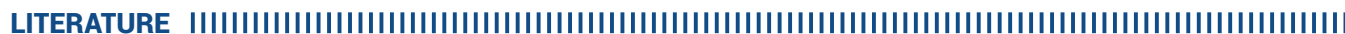

1. Karthikeyan G, Math RS, Mathew N, Shankar B, Kalaivani M, Singh S, et al. Accelerated infusion of streptokinase for the treatment of left-sided prosthetic valve thrombosis: a randomized controlled trial. Circulation. 2009 Sep 22;120(12):1108-14. https://doi.org/10.1161/CIRCULATIONAHA.109.876706

2. Dangas GD, Weitz JI, Giustino G, Makkar R, Mehran R. Prosthetic Heart Valve Thrombosis. J Am Coll Cardiol. 2016 Dec 20;68(24):2670-2689. https://doi.org/10.1016/j.jacc.2016.09.958 